The Enern is expected to reach the edge of the pack-ice in the later part of November, and to mark whales between the Greenwich meridian and South Georgia in the Dependencies of the Falkland Islands. Prof. J. T. Ruud, director of the State Institute for Whale Research, is in charge of the work, and sailing with him are Mr. R. H. Clarke, of the National Institute of Oceanography, Mr. Per Øynes, also of the State Institute, and Mr. van Utrecht, of the Netherlands Whales Research Group. December is a little early for finding the maximum number of whales, but on the other hand the work will be done by a much more powerful vessel than has yet been used for whale marking, and she is commanded by an experienced whaler, Captain M. Marthinsen. Much depends, however, on the weather.

Very little marking has been done in the Antarctic since the War, and of the pre-war marks only small numbers are now being recovered each year. The main object of the present cruise is simply to increase the number of marked whales at large, and hence the number of marks recovered; but it is also intended to test the value of certain modifications to the standard 'Discovery' mark, which have been devised by Prof. Ruud and his colleagues to improve their effectiveness, and to estimate the chances of marks being overlooked when the carcasses are treated at the factories. In July this year some experiments were made by Prof. Ruud, Mr. Clarke, and $\mathrm{Mr}$. A. Jonsgård at a whaling station at Steinshamn in Norway. Preliminary tests with the modified marks showed that they were worth extensive trials on a whale-marking voyage, and examination of the carcasses of marked whales and the position in which a mark is lodged after penetrating the blubber gave further evidence that there is little risk of injury to the whale. An account of these experiments has already been published ${ }^{2}$. It is hoped that with improved efficiency in the recovery of marks, the ratio of marks recovered to marks fired will come nearer to the ratio of total whales killed to total whales in the population. The latter ratio is at present unknown, and it is naturally of great importance. Large numbers of recovered marks are needed, not only to make the ratio of recovered marks more significant but also for studies of migration, of the rate of dispersal or interchange between the populations of different regions, and of the age and rate of growth of whales. Of course, a single new marking voyage will not dispose of all these problems, but it is hoped that it will lead at least to some progress in the investigation of this interesting mammalian population and assist the work of the International Whaling Commission.

For subsidiary work during the voyage, especially for observations on sea temperatures and the shoals of krill (Euphausia superba) on which whales and other animals feed, the Enern is equipped with a sea-thermograph, a 'fish-finder' echo sounder, a bathy thermograph, and a I-metre townet.

It has been arranged that the National Institute of Oceanography will act as co-ordinating body, and will receive all recovered marks. The Norwegian Institute will receive duplicates of all such data, and the two organizations will co-operate in examining the material. A report on the voyage will be sent to the International Whaling Commission and to the whaling companies participating in the scheme.

${ }^{1}$ Mackintosh, N. A., Nature, 169, 435 (1952).

${ }^{2}$ Ruud, J. T., Clarke, R. H., and Jonsgård, A., Norsk Hvalfangsttid., 8, 429 (1953).

\section{PHYSIOLOGY OF ATHLETIC TRAINING}

$\mathrm{A}$ LTHOUGH a large amount of time, effort and money is expended on the training of human and animal athletes whose subsequent performances are witnessed in the aggregate by thousands of spectators, it was probably the inherent interest in the subject which led the Physiology Section (I) of the British Association to devote a whole day at the Liverpool meeting to a symposium on the "Physiology of Athletic Training". The methods of training both men and animals are mainly empirical; but by having a panel of speakers made up of physiologists, active athletes, trainers and coaches of both animals and men, it was hoped that the papers and subsequent discussion would show what assessment, on a physiological basis, could be made of training methods.

Middle- and long-distance running was taken by Prof. A. Hemingway (University of Leeds) as a fairly straightforward example of athletic performance. It requires skill, but not in the sense of using specialized techniques of handling implements or of employing strategy and tactics as in complex games. The limitations to performance in running are ultimately dependent on chemical reactions in muscle. Some of the reactions are anaerobic; but they can only be used to a limited extent. If oxygen is available the overall reactions can be aerobic, and the extent to which they are used is dependent upon the oxygen supplies to the muscles. If the rate of energy liberation outstrips the available oxygen supplies, then part of the energy must be supplied by the anaerobic mechanisms. But as these are limited, fatigue must ultimately ensue, the period elapsing before its onset depending on the rate of energy liberation. The fundamental problems of the athlete are to convert his energy into locomotion with maximum efficiency and to provide as large a proportion of the energy as possible by aerobic mechanisms. To what extent does training help in solving these problems ?

Comparisons between trained and untrained men show great differences in their ability to take up oxygen. The highest rate of oxygen uptake measured on a trained athlete is $5 \cdot 3 \mathrm{l}$./ $\mathrm{min}$. when breathing atmospheric air at normal pressure. The ability to transport oxygen at this rate from the lungs to the working muscles seems to depend upon a large output of blood from the heart. Such differences as there are between the capacity of the lungs, the rate at which they can be ventilated, or the com. position of the blood, in trained and untrained men are insufficient to explain the discrepancy between their ability to take up oxygen. The main difference seems to be in the output of the heart. Recent advances in the technique of measuring the output of the heart make it possible to estimate that the maximum output may rise to about $40-501 . / \mathrm{min}$. in a first-class middle-distance runner. The severe training methods used by some long-distance runners increases the strength of both the skeletal muscles and the heart. The athlete makes optimum use of the oxygen which is available through this large blood output by running usually at a constant pace and by employing an economical style. Recent Scandinavian work illustrating the relationship between stride-length and efficiency of running was 
quoted by Prof. Hemingway. For a given pace there is an optimum length of stride. Preliminary exercise - 'limbering-up' - improves subsequent performance and seems to produce its effects through a local increase in temperature of the working muscles. Whether the change in temperature directly affects the properties of the muscle or operates by producing an increase in blood flow is still undecided.

That lack of oxygen is the main factor limiting the distance runner was stressed by Mr. Roger Bannister (St. Mary's Hospital Medical School, London), who described experiments which he had performed in Oxford upon himself and athletic colleagues. The subjects undertook severe standardized exercise on a treadmill, while breathing mixtures of oxygen and air. They were exhausted after running for about eight minutes with atmospheric air; if oxygen was added to give 33 per cent concentration, the performance was improved, while with 66 per cent oxygen the runners appeared to be able to continue indefinitely. It was suggested that because of vascular shunts in the lungs, there might be an actual reduction of the oxygen saturation of the arterial blood during severe exercise which was mitigated by enriching the air with oxygen. If so, training might be regarded as an. alternative to the use of an oxygen mask!

Training methods in current use were described by Mr. G. H. G. Dyson (chief coach, Amateur Athletic Association). 'With the aid of 'loop films', which enabled the audience to have a particular phase of movement projected repetitively, he showed the characteristic styles of champion longdistance runners, emphasizing how the stride is developed from a vigorous thrust, or drive, of the back leg. The back leg, often flexed at the knee with the foot above the level of the knee joint, is then swung forward in pendular fashion, and the runner lands almost flat-footed with the foot very little in front of the body. The length of stride is rather shorter than might be expected from body height. Training aims at developing strength, endurance, efficiency of movement and judgment of pace. Although the methods of various successful athletes may appear to differ, they are very similar in their essentials. Early training for the development of muscular strength might consist, as with the Scandinavians, in running in snow, or crosscountry running, or even running in heavy boots. This would be followed by later training in which the athlete would obtain practice in running at a speed appropriate to his race, interspersing his faster running between longer periods of slower running. Thus, in training on a track, an athlete aiming at a record performance at three or six miles $\left(5,000\right.$ or 10,000 metres) might run one lap ( $\frac{1}{4}$ mile) at racing speed and follow it by three or four laps at a slower speed. This training might be continued for two or three hours, while the athlete runs about twenty miles.

To some extent the athlete, already possessing ability, improves in strength, endurance and skill by repetition in training of a standard performance at intervals long enough to avoid fatigue. But attempts have been made to strengthen specific muscle groups by special training, and Mr. G. T. Adamson (University of Leeds) touched on this subject when he described experiments on undergraduates in which the limit of each individual's capacity to perform certain movements-for example, the number of times a beam could be 'chinned'- has been determined. The subject then makes a circuit, which contains a number of these tests, in a given time and performs each one a certain proportion-say a half or a third - of his maximum. Periodic testing showed significant improvement in performance, both for strength and endurance, and the training rate was altered accordingly. This method of training differs from that usually followed by an athlete because the amount of work preseribed for training is quantitatively adjusted to the previously assessed capacity of the subject.

Two papers on animal training emphasized a theme already raised by Mr. Bannister in discussing the physical build of athletes: runners are bred rather than made. The training of the track-racing greyhcund was described by Mr. J. K. Bateman. (Greyhound Racing Association) in a paper read by Prof. E. C. Amoroso. Great attention is paid to the diet of the puppy to ensure proper skeletal and muscular growth, and from about three months old he is given plenty of opportunity for free exercise. Even a short period off his legs during the phase of rapid growth is likely to prevent a puppy from becoming a satisfactory racing dog. When about a year old, running training begins, and the galloping distance is gradually increased until the puppy can run at full speed for about 250 yards. Regular work and good feeding are continued on a progressive scale, but the distance over which the dog runs at full speed is only gradually increased, and he will only do this occasionally. Even when the dog is fully trained and in racing trim for races of 500-700 yards, a full-speed run over a distance is only done two or three times a week.

Each day when in racing trim the dog, apart from a period of about fifteen minutes self-exercise, has a walk of about two miles at a slow trotting pace. It was interesting to hear how much less training work is undertaken by canine sprinters as compared with the corresponding human athlete. When endurance is required, as in the coursing greyhound, a great deal more road walking is undertaken. The dog does not control his speed. $\mathrm{He}$ will always go all out at the beginning of a race, and his speed diminishes as he tires, unless some slight break, as in coursing or hunting, gives opportunity for recovery. A horse can undertake long-distance races because he is controlled by the jockey, and his energy output can be spread over a period.

The importance of breeding in the production of the successful racehorse was stressed in a paper by Mr. J. L. Jarvis, the Newmarket trainer, read by Mr. W. C. Miller (Equine Research Station, Newmarket). Almost all the winners of classic races can be traced back in their pedigree to some great race mare. Mr. Jarvis outlined the sequence of training a horse for the Derby, where a combination of speed and endurance is required. Training begins with the breaking in of the horse as a yearling, and he is regularly exercised for about an hour and a half each day during his first season. The next year, in the spring, he will first be given some trotting exercise on the roads, and then steady cantering exercise which is gradually increased in pace and distance. The prime aim of this training is said to be the building up of the muscles; but at the same time the resources of the circulation are increased so that the animal is able to meet the increased capabilities of the muscle with better supplies of oxygen. Training occupies about an hour and a half each day, unless the horse is being trained for 
distance races, when it will be longer. Unlike the human athlete, running over even shortish distances at a likely racing pace does not seem to be part of the technique of horse-training. The way in which a race is actually run-the initial pace, the running for position-depends upon the jockey and not upon the horse's judgment of pace. Training is an art, declared Mr. Jarvis, and a training routine must be suited to the mental and physical constitution of each particular animal.

Finally, Mr. J. Lynas (Blackpool Football Club) and Mr. J. Egan (Leigh Football Club), two wellknown trainers and coaches of professional footballers, Association and Rugby League respectively, gave accounts of their methods of training. They made it clear that a general fitness for endurance and ability to run quickly on occasion makes only a foundation on which the particular skills of the game can be imposed. Mr. Egan analysed the duties of the different players in a team, showing, for example, how the physical and physiological requirements of a wing three-quarter in Rugby football differ from those of a forward and pointing out that, although an all-out run of fifty yards is usually a maximum, very few players are likely to undertake it ; frequently, very rapid acceleration over a few yards is more important than first-class sprinting ability. Initial training at the beginning of the season concentrates on distance running to promote endurance, and more specific practice in sprinting, kicking and ball-handling is taken according to individual requirements. While Mr. Lynas seemed less inclined to regard an Association football team as a collection of specialists, his training requirements seemed to be on similar lines, with emphasis on the practice of the skills required for the game. Both trainers regarded speed in running as unimportant in itself. Many great players have been relatively slow runners, but their knowledge of the game and anticipation has often given them actually several yards start of their opponents.

One point which emerged clearly from the papers and from the discussion was that the term 'fitness' should be applied only towards a specific end. A certain degree of muscular development and ability, through the circulation, to transport oxygen is necessary for any sustained muscular activitythis might be termed a 'general fitness'. But beyond this there must be a 'specific fitness' involving the development of particular muscles and the acquirement and use of particular skills, such as pace judgment and economy of effort for the athlete, game technique for the football player and control of the horse by the jockey.

\section{OBITUARIES}

\section{Dr. Winifred Brenchley, O.B.E.}

Dr. WINIFRED BRENCHLEY, the well-known agricultural botanist of the Rothamsted Experimental Station, died at her home at Harpenden, on October 27, after a long and crippling illness which, however, was mercifully without great pain for her. She was born on August 10, 1883 ; her father was a popular and successful schoolmaster at Camberwell, serving at one time as mayor of the Borough. In early childhood, while recovering from measles, a wellintentioned friend took her out for a drive: she caught a chill which so gravely injured her ears that she suffered all her life from deafness. But she never allowed this to interfere with her work or her social activities or with her never-failing helpfulness to her younger colleagues.

From James Allen's School, Dulwich, she went first to the Swanley Horticultural College, and then to University College, London, to study under F. W. Oliver, with whom there grew up a life-long friendship. In 1906 she went to Rothamsted, the first of the staff that A. D. Hall was then assembling, and the first woman scientist to be appointed, either there or at any other agricultural institution in the country.

She soon started investigations on plants by the water culture method which she, and afterwards her colleague Katherine Warington, developed into an instrument of remarkable effectiveness. From the outset she included metallic salts known to be toxic at high concentrations, and watched for the stimulus they were supposed to exert at low concentrations: spectrographic methods had not yet arrived, and she narrowly missed discovering the essential role of the trace elements. The earlier results are summarized in "Inorganic Plant Poisons and Stimulants", published in 1914 by the Cambridge University Press; a later revised and enlarged edition came out in 1927. The work continued, however, during all her time at Rothamsted : the last element dealt with was molybdenum.

Through Oliver's influence, Dr. Brenchley began a second group of investigations : ecological studies of the complex floras of farmed land. The effects of fertilizers in altering the competition-equilibrium between the various species in a meadow were described first in "The Manuring of Grassland for Hay" (Longmans) in 1924: but she was still continuing the work when she retired. Her studies of weeds in arable crops and grassland were brought together in "The Weeds of Farmland" (Longmans, 1920), extended later to include studies of the viability of weed seeds in the soil : she was able to show that some had remarkable powers of survival for many years. She also studied the effects on the growing plant of individual factors that make up the natural environment, especially temperature, light and nutrients. These botanical studies did not exhaust her scientific interests; she and Dr. A. D. Imms, then the Rothamsted entomologist, became great friends, and with his help she acquired considerable knowledge of insects.

Dr. Brenchley summarized the first thirty years of her work in the Rothamsted Annual Report for 1935, and the next ten years in the issue for 1939-45. She retired in September 1948, intending to write up her accumulated observations. These had been made with great care and deserved closer study than her busy working life had allowed; but her illness intervened, and it steadily grew worse to the deep regret of a wide circle of friends at Rothamsted and far beyond. E. JOHN RUSSELL

\section{Dr. Wendell C. Bennett}

Wendell C. Bennetr, a distinguished student of Peruvian archæology, died on September 6 in his forty-eighth year. His end, while swimming off the shore of Martha's Vineyard in Massachusetts, was a tragic one.

At the time of his death, Bennett occupied a number of important posts at Yale University, where 